\title{
Research of Permeable Multi-Function Treatment Agent on Concrete Surface
}

\author{
Haibo Yang ${ }^{1, a}$, Guosheng Liao ${ }^{1, b}$ and Pengfei Zhao ${ }^{1, c}$ \\ ${ }^{1}$ College of Urban Construction, Wuhan University of Science and Technology, \\ Wuhan, 430065,China \\ ª447265643@qq.com, b867887209@qq.com, 56259837@qq.com
}

Keywords: Multi-function, Surface treatment agent, Rebound strength, Carbonation depth.

\begin{abstract}
With modified Sodium silicate as the main raw material, adding a certain amount of penetrating agent, reinforcing agent, $\mathrm{pH}$ value regulators to compound different treatment agent. Brushed different treatment agent on the $\mathrm{C} 40$ standard concrete block surface at different periods, and exterminated the rebound strength and carbonation depth of the test blocks, impermeability test was also carried out. The results indicated that the best time to brush treatment agent was 7 days later after concrete demoulding, the compressive strength of $28^{\text {th }}$ day increased by $16.6 \%$, impermeable abilities raised a level, and the carbonation depth of the $60^{\text {th }}$ day reduced by $3 \mathrm{~mm}$.
\end{abstract}

\section{Introduction}

With the increasing working years of the buildings, aging damage of Concrete Buildings gets more serious, most of which due to the surface of concrete constructions. To improve the strength of concrete and durability of structure, research of protection and processing technology on concrete surface in early time is getting a lot of attention [1-2]. As the level for structure design and the quality of concrete is getting higher, common and single functioned surface treatment agent can not satisfied the demands [3], therefore, the development of Multi-function treatment agent become an inevitable trend. But the research about multifunctional surface treatment agent is less at home and abroad. Studies of ZHOU Zichang et al. [4-6] have shown that composite surface treatment agent of silicate series reacted with concrete internal component when it permeated into the concrete, forming a tight seal to prevent gas, water and ion permeating into the concrete.

In this paper, based on the modified sodium silicate as the main raw material, add a certain amount of penetrating agent, strengthening agent, $\mathrm{pH}$ regulator to compound different concrete surface treatment agent, which could penetrate into concrete faster and deeper and relate to the cement hydration products in chemical reactions. The new generated material would block pore, increase the concrete surface compactness, increasing concrete strength and effectively prevent external invasion of corrosive media. Brush different concentrations of treating agent on the surface of concrete standard test blocks, and then test rebound strength and carbonation depth in corresponding time. Analyze the rebound strength and carbonation depth to get the best ratio of surface treating agent and the best time to brush. And test the permeability of the group which performance best.

\section{Materials}

\section{Preparation of Modified Sodium Silicate}

Sodium Silicate. Sodium silicate is a kind of alkali metal silicate soluble in water, composed of different proportion of alkali metal and silicon dioxide. It's a kind of rigid inorganic cementitious material [7]. This article selects sodium silicate, modules 1.

Modifierof Sodium Silicate. Add water soluble starch, dextrin, urea, sodium tripolyphosphate and sodium sulfite into water soluble sodium polyacrylate resin solution in accordance with the appropriate proportion at room temperature, mixing it. About 1 hour later, we can get sticky, slurry modifier. 
Preparation of Modified Sodium Silicate Solution. Mix sodium silicate modifier with ordinary sodium silicate at the proportion of 1:5 at room temperature, and leave it for 24 hours.

Additives.

Table 1. Test additives.

\begin{tabular}{|cccc|}
\hline Name & Penetrating agent & Strengthening agent, & pH regulator \\
\hline $\begin{array}{c}\text { Chemical } \\
\text { composition }\end{array}$ & $\begin{array}{c}\text { Sodium } \\
\text { polyacrylate }\end{array}$ & Sodium fluosilicate & Sodium hydroxide \\
\hline Manufacture & In lab & $\begin{array}{c}\text { Reagent factory of Hedong } \\
\text { district in Tianjin red crag }\end{array}$ & $\begin{array}{c}\text { Guangzhou Yiyuan } \\
\text { environmental protection } \\
\text { technology co., LTD }\end{array}$ \\
\hline
\end{tabular}

\section{Test Scheme and Equipment}

The concrete grade is $\mathrm{C} 40$, mixing proportion is shown in Table 2

Table 2. Properties of concrete for C40.

\begin{tabular}{|cccccccc|}
\hline Composition & Water & Cement & $\begin{array}{c}\text { Mineral } \\
\text { powder }\end{array}$ & Flay ash & Sand & Stone & Admixture \\
\hline Dosage/Kg & 166 & 310 & 90 & 50 & 558 & 1210 & 6.3 \\
\hline Manufacturer & $\begin{array}{c}\text { Tap } \\
\text { water }\end{array}$ & $\begin{array}{c}\text { Ya Dong } \\
\text { P.O42.5 }\end{array}$ & Wuxin & Hanchuan & $\begin{array}{c}\text { Yangtze } \\
\text { Rive }\end{array}$ & Xianning & $\begin{array}{c}\text { Xinxiang } \\
\text { Technology }\end{array}$ \\
\hline
\end{tabular}

Main equipment are shown as follows: ZC3-A Rebound hammer, TH-1Carbonation depth gauge, Hs-4 Concrete permeability instrument.

The blocks are cured in nature, simulating the environment under the condition of current construction. Brush the treatment agent on blocks for 3 times on the $0^{\text {th }}$ day, the $3^{\text {rd }}$ day, the $7^{\text {th }}$ day and the $28^{\text {th }}$ day respectively after demoulding, and the testing time corresponding to the $3^{\text {rd }}$ day, the $7^{\text {th }}$ day, the $28^{\text {th }}$ day and the $60^{\text {th }}$ day. The groups and the formula are shown in Table 3.

Table 3. Groups and the formula.

\begin{tabular}{|c|l|}
\hline Groups & Formula \\
\hline group K & $/$ \\
\hline B & $3 \%$ Modified sodium silicate $+3 \%$ Penetrating agent \\
C & $5 \%$ Modified sodium silicate $+5 \%$ Penetrating agent \\
D & $10 \%$ Modified sodium silicate $+10 \%$ Penetrating agent \\
E & $3 \%$ Modified sodium silicate $+0.7 \%$ Fluorine sodium silicate solution $+3 \%$ Penetrating \\
& agent \\
F & $3 \%$ Modified sodium silicate $+0.7 \%$ Fluorine sodium silicate solution $+1 \%$ Sodium \\
\hline
\end{tabular}

\section{Method of Data Testing}

Rebound Strength of Concrete. Detect the rebound strength of blocks according to Technical Specification for Inspecting of Concrete Compressive Strength by Rebounded Method JGJ/T23-2011. Calculate the compressive strength by related strength test curve based on the average value of rebound strength $R_{m}$ and the carbonation depth $d_{m}$.

Detection Method Of Carbonation Depth. After rebounding strength, select the tropical section to detect the carbonation depth of concrete according to the Technical Standard for Inspection of Building Structure GB/T50344-2004. The tool would be carbonation depth gauge [8]. 


\section{Results and Discussion}

The Results and Discussion of Treatment Agent Used on Different Ages of Concrete. Rebound and do carbonation depth test on the concrete blocks at different time( the $3^{\text {th }}$ day, the the $7^{\text {th }}$ day, the $28^{\text {th }}$ day and the $60^{\text {th }}$ day ), revise the influence of rebound angel and carbonation depth , the results are shown as follows.

Results and Discussion of 3 Days.

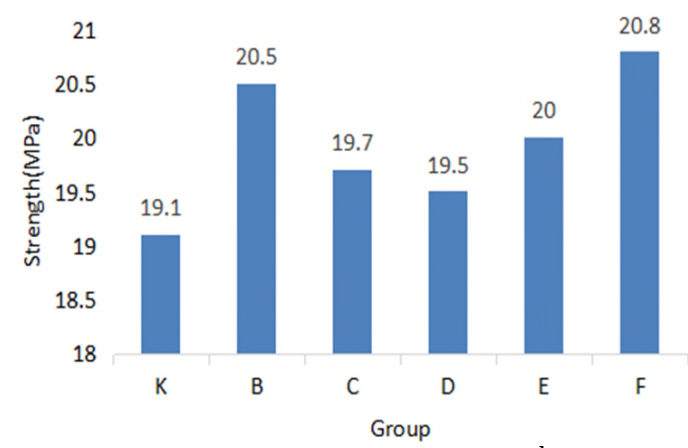

Fig. 3 Strength of the $3^{\text {th }}$ day.

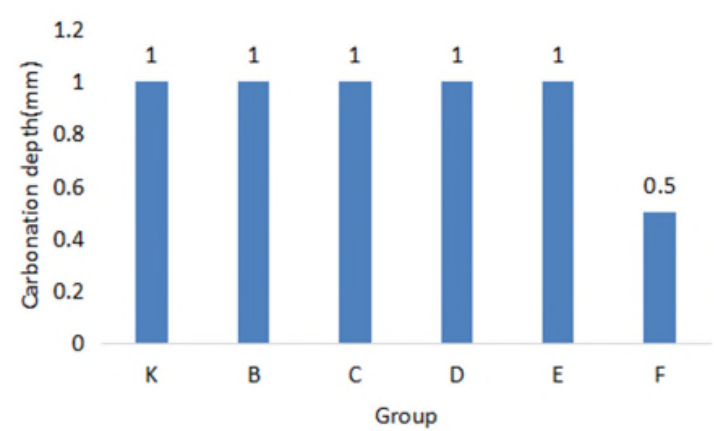

Fig. 4 Carbonation depth of the $3^{\text {th }}$ day.

As is shown in Fig. 3, the compressive strength of each group increases relative to the blank K. Modified sodium silicate (MSS) could penetrate into the concrete and react with related substance, the product can fill in the voids, increasing the density of concrete surface, thus improve the strength. We can see from group $\mathrm{B}, \mathrm{C}$ and $\mathrm{D}$, the compressive strength of concrete gets lower as the concentration of modified sodium silicate gets higher. The compressive strength declines by $3.9 \%$ from $20.5 \mathrm{MPa}$ to $19.7 \mathrm{MPa}$ when the concentration of MSS increases from $3 \%$ to $5 \%$. While the compressive strength declines by $1.0 \%$ from $19.7 \mathrm{MPa}$ to $19.5 \mathrm{MPa}$ when the concentration of MSS increases from 5\% to $10 \%$. The particle size of MSS is usually 1-6um while the hole of concrete pore size less than 0.5 um account for more than $60 \%$ of the total number of hole, which means that even the penetration agent could disperse particle size of the MSS, but most of the MSS particle size are still bigger than the hole inside concrete, so the effectively functioned MSS in the concrete are in a small number.

The Fig. 4 presents the carbonation depth of each group, the values of group 4 and group B-E are $1 \mathrm{~mm}$, while the group $\mathrm{F}$ with sodium hydroxide is $0.5 \mathrm{~mm}$. When $\mathrm{CO}_{2}$ diffuse into the concrete, it react with the sodium hydroxide brushed on the surface at first, and generates sodium carbonate. The sodium carbonate can fill the pore of concrete surface, cut off part of the carbon dioxide [9] outside, effectively reduce the carbonation depth.

Results and Discussion of 7days. As is shown in Fig. 5 and Fig. 6, Compared with the group K, the compressive strength of group B - F were notable increased, and the carbonation depth decreased. The carbonation depth of group $\mathrm{K}$ is $3 \mathrm{~mm}$, and the maximum carbonation depth of other groups is 2.5 $\mathrm{mm}$, the minimum is only $1.5 \mathrm{~mm}$. The compressive strength of group $\mathrm{K}$ is $26 \mathrm{MPa}$, the minimum of group $\mathrm{B}-\mathrm{F}$ is $27 \mathrm{MPa}$, increased by $3.8 \%$ than group $\mathrm{K}$.

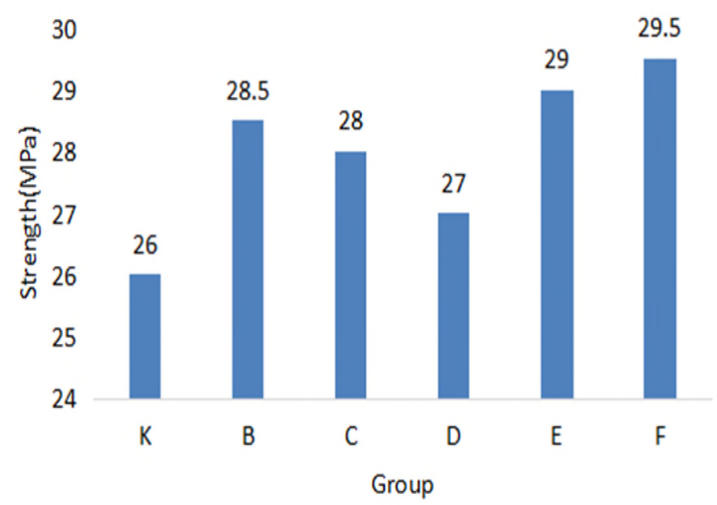

Fig. 5 Strength of the $7^{\text {th }}$ day.

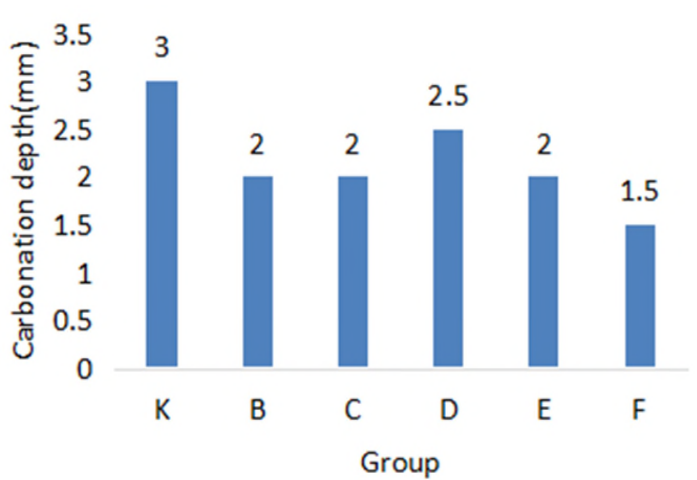

Fig. 6 Carbonation depth of the $7^{\text {th }}$ day. 
Compared with Fig. 3 and Fig. 5, the compressive strength of group E is $0.5 \mathrm{MPa}$ lower than group $\mathrm{B}$ on the $3^{\text {th }}$ day, while $0.5 \mathrm{MPa}$ higher on the $7^{\text {th }}$ day.The result indicates that the Strengthening agent react slowly with the component of concrete. The group F performed best, the compressive strength increased by $13.5 \%$ than group $\mathrm{K}$, and the carbonation depth is half of group $\mathrm{K}$. Two main reasons are as follows: first, the sodium carbonate filled the pore of concrete surface, stopping part of $\mathrm{CO}_{2}$ outside the concrete; Second, Fluorine sodium silicate reacted with the product of modified sodium silicate and concrete, and the products could also block part of the pore. Based on the above analysis, the group $F$ performed best in increasing strength and decreasing the carbonation depth.

\section{Results and Discussion of 28days.}

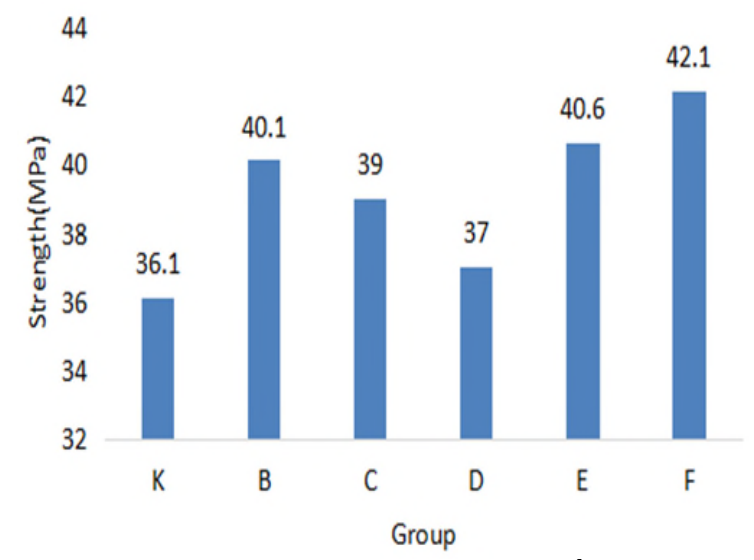

Fig. 7 Strength of the $28^{\text {th }}$ day

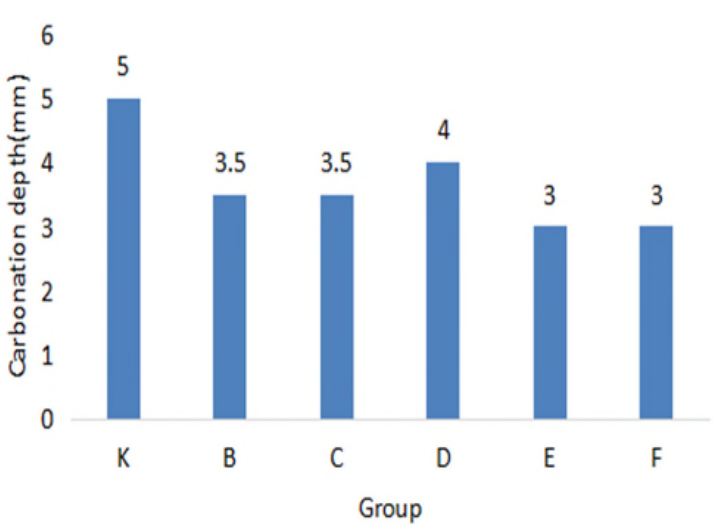

Fig. 8 Carbonation depth of the $28^{\text {th }}$ day

As is shown in Fig. 7 and Fig. 8, The strength of group B-F are higher than group K, and the carbonation depth turned out to be lower. The compressive strength of group $\mathrm{F}$ is $16.6 \%$ higher than the blank K, and the carbonation depth decreased by $2 \mathrm{~mm}$. Group D is the most uneffectively, the strength just increased by $2.5 \%$ than blank $\mathrm{K}$, and the carbonation depth decreased by $1 \mathrm{~mm}$. The MSS concentration of group $\mathrm{C}$ was $10 \%$, although penetration agent was added to dispersed the particle size of MSS, the effect of penetration agent weakened as the concentration increased, making only a small number of treatment agent penetrate into the concrete to react with related components. This resulted in the little increase in strength, and merely decrease in carbonation depth.

Results and Discussion of 60 Days. As is shown in Fig. 9, the compressive strength of concrete are above the design strength despite the later strength increasing slowly. The strength of groups B-F are all higher than the blank $\mathrm{K}$, and the strength of group $\mathrm{F}$ increased by $11.5 \%$. Based on group B-D, the strength decreased as the concentration of treatment agent increased, we could conclude that the lower concentration agent works better. Fig. 10 suggests that, the later carbonation depth of blank K increased a lot, while other groups with treatment agent used are much lower than the blank K, and group $\mathrm{E}$ and group $\mathrm{F}$ values a minimum of $4 \mathrm{~mm}$.

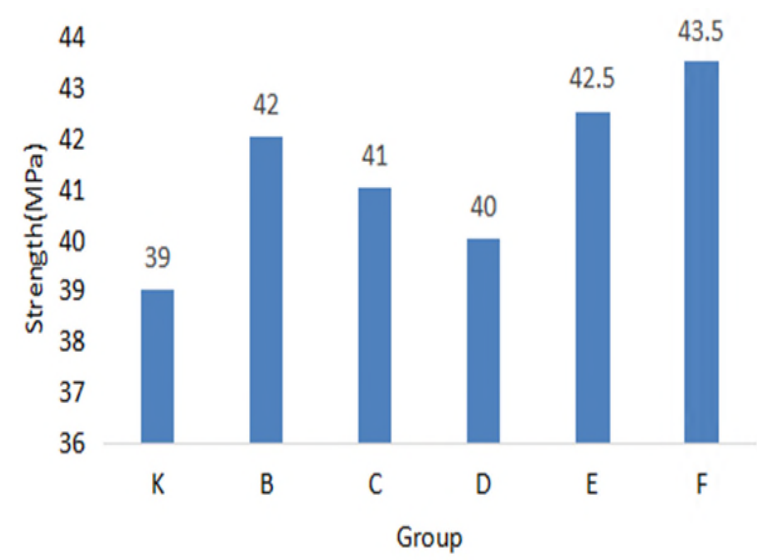

Fig. 9 Strength of the $60^{\text {th }}$ day

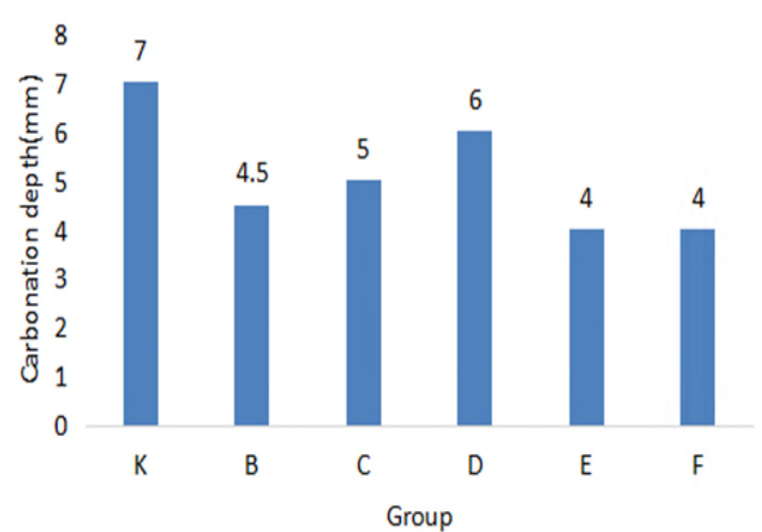

Fig. 10 Carbonation depth of the $60^{\text {th }}$ day 
The Penetration Test. The permeability resistance is an important property of concrete, it is related to the penetration of concrete as well as freeze-thaw durability and corrosion resistance [10], thus the penetration test is vital. Conduct the penetration test on group $\mathrm{F}$, as its work performance is the best, and compare the permeability resistance with blank $\mathrm{K}$. The water pressure starts from $0.1 \mathrm{MPa}$, and increase by $0.1 \mathrm{MPa}$ every 8 hours. The result is shown in Table 4.

Table 4. The result of penetration test.

\begin{tabular}{|cccc|}
\hline Group & Water pressure/MPa & Penetrated or not & Grade \\
\hline $\mathrm{K}$ & 0.9 & Yes & P8 \\
\hline $\mathrm{F}$ & 1.1 & Yes & P10 \\
\hline
\end{tabular}

As is shown in Table 4, the blank $\mathrm{K}$ started to penetrate when the water pressure increased to $0.9 \mathrm{MPa}$, the permeation resistance grade is $\mathrm{P} 8$, meeting the standard requirements. The group $\mathrm{F}$ started to penetrate when the water pressure up to $1.1 \mathrm{MPa}$, the permeation resistance grade is P10. The group $\mathrm{F}$ is one grade higher than blank $\mathrm{K}$ in permeation resistance, demonstrating that the treatment agent could increase the permeability resistance of concrete. The reason is that the product of the treatment agent reacted with concrete could block the hole inside the concrete, making it much more dense, thus stopping the channel through which the water enter inside concrete.

\section{Conclusions}

(1) The group $\mathrm{F}$ works best on concrete, the formula is $3 \%$ Modified sodium silicate $+0.7 \%$ Fluorine sodium silicate solution $+1 \%$ Sodium hydroxide solution $+3 \%$ Penetrating agent, and the best using time is the $7^{\text {th }}$ day after demoulding on consideration of comprehensive performance improvement.

(2) The permeable Multi-function treatment agent could increase the compressive strength of C40concrete by about $16.6 \%$, and decrease the carbonation depth of the $3^{\text {rd }}$ day, $7^{\text {th }}$ day, $28^{\text {th }}$ day, $60^{\text {th }}$ day by $0.5 \mathrm{~mm}, 1.5 \mathrm{~mm}, 2.0 \mathrm{~mm}$ and $3.0 \mathrm{~mm}$ respectively.

(3) The permeable Multi-function treatment agent could increase the permeation resistance grade by one grade.

\section{Acknowledgement}

This research was financially supported by the CRSRI Open Research Program(Program SN: CKWV2014211/KY).

\section{References}

[1] C. G. Bi, Discuss briefly on how to ensure the durability of reinforced concrete structure. J. Inform. Sci. Technol. 20 (2012) 384.

[2] C. F. Yuan, D. T. Niu, F. Z. Duan, The study of change of PH in Concrete simulated pore during carbonation. J. Silic. Bull. 10 (2011) 1126-1130.

[3] H. Sui, Z. G. Zhou and Y. Zhou, The development of new surface treatment. J. LiaoNing Chem. Ind. 5 (2010) 523-525.

[4] Z. C. Zhou, Z. L. Wu and S. Lu, etc. The research of hydraulic concrete surface protection treatment technology. J. Water Resour. Hydropower Technol. 10 (1995) 19.

[5] H. Z. Zhu, The research of concrete structure surface treatment technology. Archit. Technol. 11 (2007) 73-75.

[6] Y. X. Zhao, P. F. Du and W. L. Jin, Evaluation of the performance of surface treatments on concrete durability, J. Zhejiang U. Sci. A(Appl. Phys. \& Amp; Eng.), 5 (2010) 349-355. 
[7] Z. W. Jiang, Concrete structure surface protection technology. J. New Build. Mater. 2 (2004) $12-14$.

[8] L. Wu, Highway Bridges in service condition detection and assessment method research, Huazhong university of science and technology, 2006

[9] J. He, C. H. Yang and C. F. Lv et al. Sodium silicate - slag cement mortar performance of carbonation resistance. J. Silic. 3 (2010) 78-82.

[10] L. L. Zhang, B. K. Liu and B. Hu, The research of recycled concrete impermeability test. J. Hefei U. Technol. 4 (2009) 508-510. 